\title{
Identidad académica: una franquicia en construcción
}

\author{
Maite Inés Jiménez Peralta
}

Pontificia Universidad Católica de Valparaíso. Chile.

maite.jimenez@pucv.cl

Recibido: 21/11/2016

Aceptado: 30/10/2017

Publicado: 15/7/2019

\section{Resumen}

El impacto que ejercen las universidades en el desarrollo de la sociedad cobra relevancia ante las expectativas de justicia y bien común a las que anhelan los ciudadanos. El modo en que estas instituciones se vinculan con una reflexión que favorezca la creación de nuevos modelos resulta una paradoja cuando, desde la segunda mitad del siglo xx, se ha ido consolidando un capitalismo académico de la mano de una industria universitaria cuyo alcance pone en tensión un inacabado debate. Este artículo busca presentar el modo como se van construyendo identidades fragmentadas y en conflicto a partir de entrevistas realizadas a académicos. Ellos dan cuenta de la manera en que se apropian de este modelo para emerger y resignificar su posición frente a lo que ellos interpretan que significa ser un académico universitario. Cuatro repertorios articulan una identidad interpelada por racionalidades que los moldean y los organizan en una performatividad que los enajena y los termina desarraigando y convirtiendo en reproductores pasivos de modelos basados en indicadores de gestión. Urge incorporar al debate académico el modo como esta nueva forma de hacer universidad promueve un tejido social donde el rendimiento y la autogestión impregnan a los futuros profesionales, lo que fortalece modelos individualistas de sociedad que atentan contra el bienestar de sus miembros.

Palabras clave: performatividad; identidad académica; universidades chilenas; narrativas; ethos académico

\section{Resum. Identitat acadèmica: una franquicia en construcció}

L'impacte que exerceixen les universitats sobre el desenvolupament de la societat esdevé rellevant davant les expectatives de justícia i de bé comú que mostren els ciutadans. La manera com es vinculen aquestes institucions amb una reflexió que afavoreix la creació de models nous és una paradoxa, ja que, des de la segona meitat del segle xx, s'ha anat consolidant un capitalisme acadèmic per part d'una indústria universitària, l'abast del qual posa en tensió un debat inacabat. Aquest article pretén presentar com es construeixen les identitats fragmentades i en conflicte a partir d'entrevistes amb acadèmics que expliquen la seva evolució i que refermen la seva posició apropiant-se d'aquest model, però interpretant el significat d'un acadèmic universitari. Quatre repertoris articulen una identitat interpel.lada per racionalitats que els modelen i que els organitzen en una performativitat que els allunya i que els acaba desarrelant i convertint en reproductors passius de models basats en indicadors de gestió. A partir d'aquí esdevé urgent incorporar al debat acadèmic la manera com aquesta 
nova forma de fer universitat promou una xarxa social on el rendiment i l'autogestió impregnen els futurs professionals, tot enfortint models individualistes de la societat que amenacen el benestar dels seus membres.

Paraules clau: performativitat; identitat acadèmica; universitats xilenes; narratives; ethos acadèmic

\title{
Abstract. Academic identity: A franchise under construction
}

The role higher education plays in the development of society has become particularly relevant with regard to citizens' expectations of justice and the common good. However, the way in which these institutions promote the creation of new models is paradoxical given the consolidation of an academic capitalism model in the higher education industry since the second half of the twentieth century, whose impact remains an open debate. Based on interviews with academics, this article examines how fragmented and conflicting identities are being constructed. Their accounts reveal how they emerge and re-signify their position by appropriating this model, but interpreting what it means to be an academic. Four repertoires articulate an identity based on rationalities that shape and organize them into a performativity that alienates and eventually uproots them, thus transforming the academics into passive reproducers of management-based models. It is imperative that the academic debate address how this new way of doing higher education promotes a social fabric where notions of performance and self-management permeate the mindset of future professionals, thus strengthening individualistic models of society that threaten the well-being of its members.

Keywords: performativity; academic identity; Chilean universities; narratives; academic ethos

\author{
Sumario \\ 1. Introducción 4. Conclusiones \\ 2. Diseño del estudio Referencias bibliográficas
}

3. Discusiones

\section{Introducción}

En las universidades se ha instaurado un nuevo paradigma organizacional. Conceptos de eficiencia, eficacia y rendición de cuentas han colonizado el lenguaje académico y han reorganizado las relaciones en el interior de las instituciones (Marginson, 2000). En consecuencia, se ha dado espacio a disposiciones performativas que transforman la identidad académica, cuyo efecto principal es la resignificación de su papel como agente social.

En este modelo gerencial, con racionalidad económica y dominado por la doctrina neoliberal, el Estado se posiciona como un ente custodio de los recursos entregados por la sociedad. La universidad tradicionalmente comprendida como el lugar donde la sociedad reflexiona acerca de sí misma es «modernizada» hacia una autonomía financiera y una libertad de mercado bajo un mode- 
lo de capitalismo académico (Sisto, 2007; Slaughter y Leslie, 1997). El conocimiento es transformando en un bien de consumo y el académico se vuelve un obrero que trabaja en una industria universitaria.

El efecto es el rezago del conocimiento que no es transable comercialmente y la emergencia de un académico desarraigado institucionalmente, orientado hacia la producción y tensionado por un hacer que sobresatura los espacios académicos y les hace perder significado.

\subsection{Identidad académica y modelo de universidad}

La profesión académica, introducida en Latinoamérica en la segunda mitad del siglo $\mathrm{xx}$, se caracteriza por un reclutamiento y por la percepción de una cualidad de excelencia (Galaz, 2002). A finales de la centuria se vio influenciada por una globalización que se impuso a las realidades locales (Marginson, 2006), y una racionalidad neoliberal estableció nuevas formas de vinculación contractual (OCDE, 2009). Ello en el marco de una sociedad individualista regida por el éxito y la satisfacción económica (Larraín, 2005).

Se transforma la concepción de la carrera académica en una educación superior, donde la formación y el conocimiento pueden ser transados en un mercado y donde la competencia regula la calidad del sistema y sus integrantes (Rodríguez-Ponce, 2011). El énfasis en un desempeño académico con pertinencia (Naidorf, Giordana y Horn, 2007) y eficiencia introducen una racionalidad funcional (Ibarra y Porter, 2007; Sisto, 2007, Manheim, 1933 como se cita en Busquet, 2008) propia del mundo moderno e impuesta bajo políticas de incentivo económico, tanto en pregrado como en posgrado. Se llega incluso a concebir la formación de doctorado como una formación para un trabajo emprendedor e inteligente (Munita y Reyes, 2011).

La identidad académica se convierte en difusa y compleja, transformada en las diferentes relaciones que establece con un otro para coexistir materialmente en un mismo espacio histórico (Marginson, 2006; Cappello, 2015). Conlleva un estatus ontológico acerca de quién es y las tareas que demanda este rol (Guzmán-Valenzuela y Martínez, 2016). Así, como sujeto se materializa en la resolución de esta doble condición sobre «quién es» (identidad) y "qué hace» (actividades y tareas) (Cappello, 2015)

Lo anterior viene provocado porque las universidades se fortalecieron institucionalmente con la introducción de la competencia mediada por los rankings (Blasi, Romagnosi y Bonaccorsi, 2017), que homogeneizó el concepto de universidad mediante referentes comunes (Marginson y Van der Wende, 2007). Así, desde 1990, en Latinoamérica se adoptó la gestión por concursabilidad de fondos y el incentivo económico a publicaciones en revistas indexadas (Bernasconi, 2008, 2013). La antesala fue propiciada por la crisis económica de los años ochenta, donde el modelo neoliberal se presentó como la respuesta ideológica al problema y marcó la agenda social de la década posterior con un aparato estatal muy débil a la hora de impulsar políticas educativas (Acosta, 2002). 
El académico se vio interpelado hacia la rendición de cuentas para justificar la relación entre los resultados y el acceso a recursos (López, 2002), en un modelo neoliberal de universidad que cambió las relaciones entre Estado, familias y empresas (González-Casanova, 2001; Guzmán-Valenzuela y Martínez, 2016). Este capitalismo universitario transformó las actividades de la educación superior en mercancías (López, 2002), y una forma de gestión asimilada como new public management (Hood, 1995) reorganizó las estructuras institucionales y las formas de gobierno del interior de las universidades (Court, 2004).

Así, la cultura educativa organizada según la libertad académica (academic freedom), la colegialidad (colegiallity) y la excelencia (scholarship) (Galaz, 1999) es cuestionada, y nuevas formas de financiamiento (neointervencionismo) producen la necesidad de flexibilizar las formas de contratación de la planta académica (López, 2002; Macfarlane, 2011; Sisto, 2007).

Lo correcto y lo bueno es redefinido por la hegemonía del discurso neoliberal (Petersen y O'Flynn, 2007), lo que provoca la aparición de un nuevo sujeto académico modelado por un sistema que lo regula mediante incentivos económicos (Ibarra-Colado, 2002; Ibarra-Colado y Porter, 2007). Esta nueva subjetividad derivó en la fragilización de la identidad académica, al estar demandados por narrativas diversas y en conflicto (Guzmán-Valenzuela y Barnett, 2013). Así, cabe reflexionar sobre cómo el modelo neoliberal tensiona, presiona y constriñe la emergencia de determinadas identidades universitarias, saturando el hacer académico de significados y desdibujando su sentido.

\section{Diseño del estudio}

Reconociendo que, en los espacios cotidianos, los significados se concretan en las relaciones sociales que dan origen a la experiencia subjetiva (Sisto, 2008) $y$ en el lenguaje se generan condiciones para que se vincule un contexto y un ambiente, la pregunta que guía el estudio es cómo subjetiviza el sujeto la articulación de una estructura propuesta por la normativa. Así, cabe explorar de qué modo el académico performa su identidad en la resolución de las tensiones que le provoca un sistema que lo ha instrumentalizado.

Considerando que las personas, cuando hablan, hacen referencia a elementos provistos por su historia - lo que constituye un patchwork desde varios referentes-, se constituyen como unidad de análisis las narrativas identitarias de los académicos, ya que son empleadas en la construcción de explicaciones de los acontecimientos (Rodrigo-Alsina, 2009; Castillo y Reyes, 2013) y, como tales, entregan los elementos o las piezas a los que recurren para performar una identidad en el contexto de una universidad transformada. Por esta razón, se exploró desde ellas la comprensión que ellos tienen del sistema.

El estudio se realizó en Chile, país que se caracterizó por su política neoliberal y cuyos efectos han generado un duro debate y un conflicto social en la última década. Se describe como un sistema estratificado y abierto al mercado, 
por ello se seleccionaron aquellas instituciones que fueron escenario privilegiado de estos cambios y que respondieron a las actividades tradicionales asignadas a ellas: docencia e investigación. La validación de este criterio se cumple entre aquellas acreditadas por la ley 20.129, incluidas las áreas de investigación y posgrado, que completan nueve instituciones: seis privadas y tres estatales. Todas ellas ofertan programas de doctorado, realizan formación profesional en las áreas definidas por la OCDE y están situadas en el tramo más alto de acreditación (de cinco a siete años).

Los hablantes, reclutados desde estas nueve instituciones, son académicos cuya formación superior estuvo afectada por el contexto derivado de la reforma educacional de 1981. Para ello se consideró que pertenecieran a los claustros de doctorado, estuvieran dentro del rango etario entre 35 y 55 años y evidenciaran actividad académica reflejada en publicaciones y proyectos. Se resguardaron condiciones de diversidad de género y disciplinarias.

Se realizó un muestreo teórico hasta la saturación de los datos, valor que se alcanzó con cinco académicos, sin embargo se extendieron a nueve los entrevistados para abarcar todas las instituciones. Ello permitió producir aquellos datos pertinentes para que emergiera la teoría (Charmaz, 2006). La representatividad de los sujetos no vino dada por su número, sino por su capacidad de producir un efecto discursivo desde el rol que se situaban como hablantes. Para este estudio, sus propiedades antecedían al académico como sujeto, pues este último encuentra sus posibilidades de agencia en un discurso comunitario saturado. Y desde allí, en su contexto, la experiencia se materializa y se compromete con la subjetivación del yo (Butler, 2004; Davies, 2000).

\subsection{Producción y análisis de los datos}

Para la producción de datos se utilizó la técnica de la entrevista, que permitió realizar el registro de la narrativa identitaria desde los hablantes (Alvesson, 1999). El tipo de entrevista que se aplicó fue la activa-reflexiva (Denzin, 2001; Holstein y Gubrium, 1995, 2006), para lograr una interacción en la cual los partícipes (entrevistador/a y entrevistado/a) fueran asumidos como sujetos que interactuaban abiertamente, aunque guiados temáticamente por una pauta flexible concebida como un dispositivo dialógico que permitía revelar procesos de construcción de sí mismo (De Gaulejac, 2002; Denzin, 2001; Guba y Lincoln, 2008), lo que facilitaba la exploración de las relaciones dialécticas entre agencia y estructura. Su uso visualizaba que la forma en que se contaban las experiencias estaba mediada por múltiples historias enlazadas en una racionalidad narrativa que la hacía posible, de tal forma que se iban formando sentimientos y acciones y se daba significado a las prácticas cotidianas (Polkinghorne, 1988; Riessman, 2008).

Como herramienta de análisis se usaron los repertorios interpretativos (RI) (Potter y Wetherell, 1996) que emergían de la interacción del académico con la universidad. Estos RI son unidades lingüísticas compuestas por elementos que los hablantes utilizan para la construcción de versiones de las acciones y 
los fenómenos. Permiten ir extendiendo un posicionamiento del sujeto que se expresa como diferentes identidades que utiliza el hablante para desplegarse en el discurso. Así, la identidad del hablante es construida por diferentes tipos de personas (Reynolds, Wetherell y Taylor, 2007).

El discurso en comunidad queda expresado como un compromiso continuo relacionado con lo que Butler (1990) ha denominado «matrices contingentes de inteligibilidad». La reiteración de prácticas que se circunscriben a posibilidades culturales provoca que esta subjetividad se vuelva performativa. En este caso, el proceso de hacer (im)posible el convertirse en otros para permitir nuevos posicionamientos de sujeto (Petersen, 2012) queda fuertemente influenciado por una comunidad académica.

\section{Discusiones}

La estrategia utilizada por los hablantes está marcada por una sobreexplotación del sujeto, quien se vuelve amo y esclavo en las narrativas. Esto es lo que ByungChul (2017) ha llamado «sociedad del rendimiento marcada por la autoexplotación del sujeto», debido a la naturalización del modelo neoliberal. El académico utiliza un discurso híbrido entre una racionalidad económica, donde responder a las demandas del sistema es un signo de los tiempos (Ibarra-Colado, 2002), y otro tipo de racionalidad heredada de la tradición universitaria y que alude a un sentido de trascendencia y elitismo intelectual (Bourdieu, 2012). Los repertorios se caracterizan por el uso de la reiteración para presentar, confirmar y reafirmar la presencia de un sujeto académico en ellos, como una estrategia para compensar la inestabilidad producto de las contradicciones que están formando este discurso híbrido.

Hay cuatro repertorios que describen a un académico, son los siguientes: gestor, posicionado en un track, posicionado en una identidad inacabada y que finalmente se convierte en una franquicia para la institución a medida que se vuelve reconocible dentro del sistema.

\section{Repertorio 1: El académico gestor}

La universidad emerge como un empleador que exige productos transables en un sistema de mercado. Se quiebra la idea de comunidad como espacio de convivencia intelectual $y$, como señala uno de los entrevistados (mujer, universidad no estatal, área humanista), el académico se convierte en «otro tipo de empleado, otro tipo de profesional más». El sentido de rendimiento adquiere un carácter ontológico y el sujeto se constituye como académico desde el (mal)estar en un continuo proceso de autovalidación (Byung-Chul, 2017). Esto tensiona el modelo de elitismo intelectual, pues es en el acto continuo de producir y no en el producto en sí donde el académico se logra constituir como tal.

El discurso es resuelto por una forma híbrida del mismo. Este hablante termina su frase con «últimamente, a través de este sistema de mercado que tienen las universidades de premiar el producto, por lo tanto, yo creo que el académico como tal es otra persona no más, no es el que hace clases». Así, 
el académico se reinventa a sí mismo para posicionarse en el sistema y emerge como un gestor. Esta imagen busca disimular el valor comercial de dicha producción. El académico como gestor es un ser con autonomía y capacidad de establecer reglas propias, capacidad que se incrementa con el prestigio y una excelencia medible a través de los indicadores del sistema. "O sea, uno gestiona su laboratorio, uno gestiona la manera que rinden, uno gestiona los proyectos a los cuales postula, uno gestiona su sueldo también" (hombre, universidad no estatal, área científica).

El académico ya no es el elitista intelectual de Bourdieu (Homo academicus) ni el capitalista de Ibarra-Colado (Homo economicus), sino que se posiciona discursivamente a sí mismo dentro de la red del sistema. Aunque el sistema universitario chileno es complejo, el discurso académico se vuelve homogéneo y saturado por un posicionamiento desde el agenciamiento.

El liderazgo de las instituciones es afectado por el acceso a recursos como efecto de una institucionalidad neoliberal, y la tensión sobre el sujeto académico lo obliga a tomar posiciones. El fragmento hace explícitas las nuevas formas de relación institucional que señala Marginson (2000) con una universidad preexistente al sujeto y manifestada en las expresiones «lo que quiere» $\mathrm{y}$ «quiere mejorar».

[...] en la universidad, que lo que quiere al contratar doctores es mejorar los índices y los rankings y las publicaciones. Entonces te contratan estos doctores. Yo conozco a colegas que han sido contratados por esta escuela solo para mejorar los indicadores de publicación. Entonces, yo creo que eso sí, ya, está bien, pero yo creo que hay algo más. O sea, no es solamente por tener seis publicaciones ISI..., no. Yo creo que, de verdad, creo... Yo creo que un doctor tiene que, además de ser productivo en esos términos, tiene que abrir ese espacio de investigación, y en esta escuela esos espacios están muy reducidos y muy relacionados con personas superconcretas. (Mujer, universidad estatal, área humanista)

La estrategia discursiva de reiteración se cumple en una tríada que presenta, confirma y reafirma la imagen de un sujeto objeto. El académico es descrito como un sujeto funcional que establece un vínculo instrumental con la institución. Lo confirma la certeza de que es contratado para responder a una racionalidad económica. Es decir, es considerado un artefacto productor de números. Finalmente, esta consideración se reafirma cuando señala: «Yo conozco a colegas que han sido contratados por esta escuela solo para mejorar los indicadores de publicación». La construcción de un otro, como sujeto humano, está ausente, y el valor de este radica en su capacidad implícita de mejorar los indicadores (Court, 2004).

El académico se convierte en un obrero más donde su aporte (o valor) está explícito. Pese a ello, hay inestabilidad y tensión en el discurso, cuya posición ambigua queda plasmada en la expresión «[...] yo creo que eso sí, ya, está bien, pero yo creo que hay algo más». Ese "algo más» recurre a la tradición académica y busca posicionarse. De esta forma, el sujeto se hace creíble para sí, 
transcribe el contexto y lo inscribe en su propia narrativa para hacerse reconocible (Butler, 2004).

La argumentación de exigirse y no quedarse en el cumplimiento de las metas se hace plausible. Se construye discursivamente un académico desde una tradición que reclama tomar distancia intelectual de lo contingente y de la misma universidad. El académico se sabe (y acepta ser) parte de una rutina productiva, pero se posiciona más allá, según sus propios intereses (Marginson, 2006). No hay rebelión, se acatan las reglas de productividad con la promesa de tomar distancia del modelo y ganar autonomía. La sujeción performativa opera con claridad, ya que se subordina para encontrarse a sí mismo (Butler, 2004). En palabras de los hablantes: «Bueno, este país es supercompetitivo. O sea, ganarse un FONDECYT no es fácil, todos quieren ganarse los FONDECYT, y los FONDECYT son los que mayores ingresos te traen para movilidad y ser libre en tu investigación» (hombre, universidad estatal, área humanista).

La estrategia discursiva de reiteración opera. Se presenta la competitividad, se confirma con la dificultad de ganarse proyectos y se reafirma mediante la funcionalidad de acatar esta lógica («ser libre en tu investigación»). La referencia a la libertad en un párrafo que alude a la competitividad resulta llamativa, pues para competir hay que ajustarse a las reglas, pero se hace para ser libre. Lo implícito en el texto es que hay espacios de investigación que no se relacionan con esa promesa, y por tanto no son competitivos, así los académicos dan testimonio de que las áreas de ciencias son más productivas que las áreas de humanidades, con lo que los estratos académicos son fragmentados de acuerdo con el acceso a recursos y con el poder. Discursivamente, los recursos se distribuyen en función de los méritos y del esfuerzo personal (coherente con el modelo neoliberal), sin embargo todo resulta ser un espejismo. Investigaciones cortas, publicaciones rápidas y resultados ya comprobados dan energía a una maquinaria apta para la producción de prestigio académico (Marginson y Van der Wende, 2007).

Se escribe poco y eso, de nuevo, tendría que ver con unos sistemas de financiamiento, unas estructuras de investigación y unas posibilidades... Eh... Sí..., hasta cierto punto. Yo diría que, en los últimos cinco años en el caso chileno, las publicaciones se han disparado... La calidad de las publicaciones... en...., por lo menos en algunas instituciones, no quiero decir en todas, la calidad de las publicaciones es de nivel internacional. (Hombre, universidad no estatal, área humanista)

El académico se hace reconocible gracias a una red de negocios que le permite ampliar sus posibilidades de producción y posicionarse en un circuito intelectual de poder académico. Se naturaliza la exigencia por rendir y cumplir un estándar (Byung-Chul, 2017) y se confirma su vínculo con la vida académica, lo que reafirma la imagen del gestor. Continúa la narrativa argumentando que «nos leemos poco, pero no nos leemos menos de los que se leen afuera, o sea, cada investigador está en su centímetro cuadrado trabajando». Sin embar- 
go, lejos de reprochar dicha circunstancia, justifica en una condición de época que lo hace ineludible, señalando: «Pero tiene que ver con los modos de producción de conocimiento hoy día, y con producciones aceleradas, y lo que permiten y no permiten». La declaración continúa reconociendo una ruptura histórica y la atribuye a que «no funciona».

Se hace expresa una mirada funcional y pragmática acerca de cómo funciona el sistema. La estratificación dicotómica entre buenos y malos pone a Chile a la par con sistemas de otras latitudes, pero a la vez posiciona al hablante. Finalmente, pese a los juicios negativos, la estrategia de reiteración y los ajustes para sostener un discurso inestable provocan que no se adopte una posición de crítica, sino que solo se constate una realidad que existe y excede al académico, lo que le permite organizar una matriz de inteligibilidad que lo hace reconocible ante otro (Butler, 1990)

El sujeto percibe un cambio y una realidad que supera la simple contingencia nacional. «Entonces, te están orientando hacia donde están los recursos, donde están todas las, todas las zanahorias habidas y por haber que te aparecen en este tema. En este caso, educación, incentivos, etc., etc.» (hombre, universidad no estatal, área científica). Ello denota un grado de sometimiento. Sin embargo, este sujeto sujetado a un sistema es a la vez socio de este, pues no se trata de un sometimiento pasivo, ya que si escoge someterse puede acceder a nuevas oportunidades. Va emergiendo un académico en conflicto, puesto que queda entrampado entre un académico docente y un académico investigador subordinado a políticas de un aparato estatal. Esta tensión proviene del esfuerzo de ajustar discursos que obedecen a diferentes racionalidades que muchas veces quedan confrontadas. Para mantener la hibridación, el académico debe esforzarse continuamente utilizando la reiteración.

La separación entre lo docente y la investigación va dando cuenta de estas estrategias con un sujeto que se describe fragmentado y hasta cierto punto sometido. El resultado es la exageración de la individualidad donde el académico es gestor en sus espacios locales de acción. En consecuencia, la universidad, más que un espacio comunitario, se convierte en un empleador que regula el desempeño de sus trabajadores mediante premios y castigos. El académico usa el prestigio como medida de cambio para negociar sus espacios de libertad.

\section{Repertorio 2: El track académico}

En este segundo repertorio se destaca una institucionalidad muy compleja, en la cual coexisten diferentes formas de comprender la universidad: «Eso lo estoy haciendo yo ahora recientemente hace tres años... publicando, participando del modo como esta universidad ha fijado es... y se define la carrera académica. Nosotros tenemos unos tracks acá [...]» (hombre, universidad no estatal, área humanista).

El sistema se ha vuelto múltiple, fragmentado, heterogéneo y elitista, lo que ha creado estratos (o pseudoestirpes) entre los académicos debido a la masificación y a la contraposición entre libertad y regulación. En docencia o en investigación se presenta una dicotomía mediante la cual los académicos 
hablantes se posicionan con un grado de poder. Se reafirma con ello la pluralidad en las narrativas identitarias, donde la universidad deja de ser un discurso monolítico (Sisto, 2007). La ambigüedad conceptual facilita las estrategias discursivas que buscan sostener el discurso híbrido.

El sistema se presenta segmentado bajo criterios de rendimiento, no solo institucional, sino también disciplinario. Los límites se han roto y el sistema se ha reorganizado: «no te podrías esperar que las carreras de Diseño sacaran unos tremendos índices de productividad por investigación» (mujer, universidad estatal, área humanística).

Ello lleva implícito que el sistema se mueva de forma estratégica y la investigación se convierta en una actividad que aporta una competitividad comercial. La reiteración sostiene un discurso donde el académico emerge desde una actividad de investigación sustentada en una racionalidad económica. Así, se afirma lo siguiente: "La investigación tiene que ver con el mercado» (mujer, universidad estatal, área humanística). Se genera una jerarquía que reconoce disciplinas «valiosas» y otras que no lo son tanto, como por ejemplo las artes. La tensión con la racionalidad académica se manifiesta en la descripción de relaciones de poder disciplinario. La expresión «áreas más fuertes» como una impronta disciplinaria a la cual se refirieron Becher y Trowler (2001) mediante la expresión «tribus académicas» da cuenta de una tradición presente en el discurso.

O sea, la gente está haciendo apuestas estratégicas. Entonces, si me acredito en investigación, luego pongo el sello y se lo ofrezco a mis estudiantes. Hay una que es la..., si no me equivoco, la única universidad privada acreditada en investigación [nombre eliminado]. Tú escuchas la propaganda de la [nombre eliminado] y te dicen: «única universidad privada acreditada en investigación», y eso es un sello de garantía. Entonces, esto tiene que ver con el mercado. La investigación tiene que ver con el mercado. Entonces, la fragmentación es entre universidades pero también dentro de, dentro de cada universidad, según las áreas más desarrolladas, que generalmente las más fuertes son el área de las ciencias duras. ¿Y el resto? No sé. Estoy pensando en, no sé, en arte, en música... Es muy difícil que se realice investigación en esas áreas disciplinarias o en áreas como la Administración pública, por ejemplo, en donde el conocimiento práctico es más importante que un conocimiento científico puro. (Mujer, universidad estatal, área humanística)

Esta creación discursiva de núcleos segmenta y estratifica de tal manera la comunidad académica que, aunque las plantas docentes hayan aumentado, se produce una distinción entre académicos y, en palabras de uno de los hablantes, «profesionales de la docencia». Los primeros son posicionados discursiva e identitariamente como poseedores de una «certificación válida y legítima en el mundo académico", los segundos, en cambio, no son reconocidos como tales. Esta heterorreferenciación aparece reiteradamente en los distintos hablantes, de modo que se presenta un académico que se forma y hace carrera en «el track» (aquello) que la comunidad determina que le es propio. El académico debe negociar dentro de las redes de poder que discursivamente adquiere a cambio de su subordinación a las reglas de mercado. 
«O sea, te da fondos para que empieces alguna investigación, empiece a correr la máquina y empieces a generar productos de esta investigación. Es recién ahí que tú puedes postular a un fondo externo, ¿cachay?» (mujer, universidad estatal, área científica). La racionalidad económica se hace presente en criterios pragmáticos y funcionales y el malestar que esto produce es acallado, ya que se entiende que todos ellos y sin distinción «pueden optar a este tipo de cosas». Sin embargo, el cierre no logra estabilizar el discurso, y el académico aparece como un sujeto en movimiento, inacabado y presente sin materialidad. Ello se desliza en la frase: «Lo que sí he visto es que la gente que hace poca investigación, cada vez que viaja, alardea como loco. Como si quisieran mostrarle a todo el mundo que ellos también se mueven, ¿cachay?».

La identidad se construye sobre la base de logros, pero no de cualquier tipo de logros, sino de aquellos que la comunidad reconoce y gracias a los cuales un académico con recursos se convierte en un emprendedor (Ibarra-Colado, 2002). El prestigio se vuelve el motor de esta máquina de investigación y comienza a administrar equipos de trabajo con el fin de generar nuevas investigaciones.

\section{Repertorio 3: El académico inconcluso}

En este tercer repertorio el académico se posiciona como polifacético, autónomo y gestor de su propio quehacer: «[...] todos se mueven pa' todos lados. Es como la constante que tú te mueves y viajas, y tienes proyectos, pagas tus cosas, tienes tus laboratorios, pagas a tus estudiantes» (hombre, universidad no estatal, área científica-tecnológica).

El académico se mantiene en un flujo constante de movimiento y productividad donde su identidad está en constante cuestionamiento. Tiene una agenda que va desarrollando a medida que su capacidad de gestión le va proveyendo de la autonomía suficiente para alcanzar su objetivo. Al mismo tiempo que adopta una posición de mayor empoderamiento, se convierte en una persona más crítica respecto al sistema. Se produce un antagonismo entre la percepción de una estructura que demanda productividad como condición de membresía en el sistema y una memoria, aún presente en las instituciones, de un tiempo de mayor flexibilidad. Hay una tensión implícita entre una socialización y un sometimiento a un grupo científico (Blasi y Romagnosi, 2012) y el hecho de mantenerse diferenciado del mismo para hacerse visible:

[...] el profesional que está llegando a ocupar un cargo académico está mucho más preparado que lo que nosotros estuvimos, y yo estuve, y hemos estado muchos otros cuando empezamos en este medio, o sea, te digo, este cuento antes no era así, o sea, eh... no po, uno llegaba a la universidad, ganabai un concurso, entrabai, te mandaban pa' afuera, si tenías, si tenías suerte de irte para afuera, aprendías algo que tú lo que aprendías era para entregárselo a una carrera, pa' hacer una investigación ahí, ahí no más, o sea, la investigación era tu compañero, pero hoy día no po'. Hoy día es una necesidad. El profesor que no tiene investigación, que no tiene proyectos, está mal, o sea, aquí todos tienen que tener proyectos, eh, y los jóvenes todos tienen que cumplir al cien por cien con su famoso convenio de desempeño, que..., que es bastante, 
como se dice..., bastante frío de pensar [...]. (Mujer, universidad estatal, área científica)

El académico se percibe sometido a la contingencia (Acosta, 2002), con una actividad de investigación que se transformó de "compañera» a convertirse en una «necesidad». Al ser una necesidad, se vuelve un objeto funcional para conseguir un propósito, a diferencia de la noción de compañera, que se vincula a una relación afectivo-vivencial (Cappello, 2015). Los académicos, así, se mueven entre dos realidades: una histórica que genera una estructura que provee una racionalidad funcional a la que se somete en la búsqueda de bienestar económico y otra que distribuye cuotas de poder y de prestigio, en una narrativa emancipada de tradición académica que sustenta su proyecto de vida (Guzmán-Valenzuela y Barnett, 2013). Esta discontinuidad provoca que el académico deba tomar una posición que se debate entre lo que algunos han igualado a la noción de mercenario y una reformulación personal del significado de la propia carrera académica (Marginson, 2000, 2006).

La búsqueda de autonomía (libertad) se va definiendo desde una racionalidad connatural a la carrera académica. Así, su identidad es reconocible por cuanto se ajusta a un marco establecido. Este sometimiento provoca que, aunque se vea libre, se explote a sí mismo hasta el colapso (Byung-Chul, 2017):

La profesión académica en la literatura internacional se rige fundamentalmente por aquello..., por un entrenamiento típicamente formal de unos estudios de pregrado y posteriormente de posgrado, con un desarrollo de unas investigaciones de alto nivel que luego se publican y se comparten. $\mathrm{Y}$ uno primero se incorpora como un profesor junior dentro de un track de desarrollo, en que uno va desarrollando un conjunto de funciones en la institución que tienen que ver con la docencia, la investigación y la gestión, primero supervisado y después con un creciente nivel de autonomía. Y luego uno va ganando posiciones de acuerdo con las carreras que sean fijadas. (Hombre, universidad no estatal, área humanista)

Su identidad se resuelve en el modo como se posiciona en el intertexto de su discurso, puesto que, si bien está sometido a un sistema, es a la vez agente del mismo, ya que tiene muy claro qué es lo que debe hacer y cómo lo debe hacer para alcanzar su desarrollo: «Eso lo estoy haciendo yo ahora recientemente hace tres años..., publicando, participando del modo como esta universidad ha fijado es... y se define la carrera académica». Esta frase presenta un fuerte carácter performativo, ya que el entrevistado toma una posición de control y subordinación en su relato (Butler, 1990).

$\mathrm{Su}$ proyección depende únicamente de la rigurosidad con que se adscribe a estas reglas enunciadas como publicar, participar de las instancias definidas por la universidad, y su vínculo con redes de investigación de alto nivel. Su identidad se sedimenta entre las diferentes relaciones y vínculos que es capaz de establecer dentro del sistema (Cappello, 2015).

El pragmatismo y la funcionalidad que organizan la vida académica se manifiestan en una reconceptualización del vínculo contractual con un 
empleador llamado universidad, y por tanto sujeto a las reglas de un mercado laboral. El efecto es la desvinculación del académico con la institución, pues el vínculo es solo contractual, sin componente afectivo, y sustentado solo en el rendimiento evidenciable.

La universidad como un lugar para el pensamiento privilegiado (Bourdieu, 2012) parece diluirse en las lógicas de una nueva forma de institucionalidad, lo que obliga al académico a realizar correcciones en su discurso. Así, el siguiente fragmento muestra que la palabra pago es reemplazada por el término incentivo económico. Este cambio, más que tratarse de un eufemismo, provoca una diferencia entre la empresa y la universidad. Es una narrativa donde prima el discurso tradicional y se despliega la libertad académica como un valor.

[...] la gracia de la universidad es esa libertad académica. Así que en ese sentido casi todo lo que hagamos por iniciativa propia, llámale emprendimiento si quieres, algunas de esas cosas pueden llevar dinero de por medio y otras no. Por eso, hasta ahí yo consideraría la analogía, ¿no cierto? Ahora, hay ciertas dimensiones del quehacer académico que comportan incentivos monetarios y acumulación de recursos no personales, pero sí laboratorios, equipamiento, espacio, qué se yo... Claro, eh, cada académico hace su carrera trabajando en grupos, logrando objetivos, consiguiendo estos incentivos para poder financiar su investigación y su quehacer, eh... Pero las diferencias con una PYME yo creo que son bastante importantes. Una PYME, como toda empresa, busca maximizar todas las utilidades, y un académico, en mayor o menor medida por lo menos, pone primero toda esta mecánica de incentivos como, bueno, yo procuro ponerla como un medio pa' otra cosa y no como un fin en sí mismo. (Hombre, universidad no estatal, área científica)

Esta imagen de incentivos relacionados con la investigación construye un discurso fragilizado por la imagen de un académico administrador que demanda una resolución dando cuenta de la tensión y del anhelo por generar espacios de resistencia respecto de un modelo mercantil de educación superior:

Yo estoy pasando por esa encrucijada ahora mismo, porque no veo mi propio futuro académico sin ser yo el que trabaja directamente con alumnos en los temas que estoy investigando. No quiero decir que no pueda delegar, pero quiero participar en ello, no me quiero desprender de esa actividad. De lo contrario me hubiera quedado en el mundo de la empresa. (Hombre, universidad no estatal, área científica)

Así, en la narrativa se revela sutilmente que el contexto fragiliza límites de su identidad (De Gaulejac, 2002). Paradójicamente, el académico, para materializarse, debe irse disolviendo en una red de relaciones entre proyectos, publicaciones y núcleos de trabajo como una forma de sostener el acceso a los incentivos monetarios o a otros recursos. Hay una identidad que nunca termina de resolverse, por cuanto el sujeto está en un continuo proceso de autoheterovalidación. 


\section{Repertorio 4: El académico como franquicia}

El académico adopta una posición más distante frente a instituciones que manifiestan relaciones de competencia entre ellas: «[...] hay mucho que te da esto de ser $\mathrm{ABC1}$. Esta red que se maneja, estos círculos de poderes, estas redes que se manejan ahí. Eh... es una componente importante que te da el sustento para ver las cosas» (mujer, universidad estatal, área humanidades).

Se sostiene el anhelo del académico por una autonomía que justifica como necesaria para el establecimiento de redes que le permitan agenciarse. Se convierte a sí mismo en una franquicia, una "marca» que asegura a la institución una posición en los rankings de prestigio.

El vínculo institucional queda simplificado al de un auspiciador, pero no participa activamente de su articulación en las redes. El discurso híbrido se mantiene, pero con una narrativa donde se posicionan la globalización y el avance tecnológico (Ibarra-Colado, 2002; Larraín, 2005). El sujeto se desmaterializa y tiende un puente para justificar relaciones que, sin requerir una presencialidad, favorecen la producción: «[...] cuando hablo de redes hablo de eso, de escribir un trabajo de investigación conjuntamente» (hombre, universidad no estatal, área científica). La pertenencia a redes estratégicas fortalece su posibilidad de ser reconocido como académico.

La autonomía otorga la capacidad de ser propietario de los propios proyectos. Esta estrategia da al académico un poder dentro del sistema, al establecer la cualidad de ser «una profesión distinta a otras industrias». El académico, como sujeto, se posiciona con la capacidad de establecer una negociación entre lo que la universidad requiere y sus propias metas, lo que le entrega poder frente a la institución, donde la identidad queda condicionada a sus posibilidades de estar en dicha red:

En el caso chileno somos supercompetitivos digamos entre casas de estudio, y se da esta cosa de «¿de dónde vienes?», ¿̇ah? Eh... eh... Es una profesión distinta a otras industrias, tiene enorme autonomía, y yo creo que parte de la..., en el caso chileno, nosotros hemos dado especial autonomía a los profesores a propósito del tipo de financiamiento de la investigación que entregamos. Eso no pasa en todas partes del mundo, donde hay mayor combinación entre las instituciones y los grants. Digamos que acá en Chile uno tiene un proyecto y se lo puede llevar a otra institución. (Mujer, universidad no estatal, área científica)

Los académicos se van vinculando a estas redes de diferentes formas, todas mediadas por el valor que pueden aportar hacia una estrategia de desarrollo académico. El resultado está formado por sujetos que se describen en un ambiente de trabajo con relaciones que son muchas veces antagónicas, provistas de una racionalidad pragmática y de competitividad en referencia a los recursos. El discurso híbrido se hace inestable entre una comunidad que tanto da un "sentido de apoyo» como se desarrolla en «un ambiente extremadamente competitivo». La racionalidad económica introduce como argumento una actuación desde una expectativa de beneficio mutuo (Ibarra-Colado, 2002). 
Así pues, hacer proyectos y publicar en red crea estructuras de agenciamiento donde, a medida que los académicos van consolidando su valor en el medio, coexisten relaciones afectivas y un modelo de negocios, ambos orientados al desarrollo académico: «es gente que hace su vida académica calculando cada paso que da».

Se fortalece así un estilo de trabajo donde lo global resulta más próximo que lo local y donde un académico que está en otro continente es más cercano que el colega de oficina. Emerge un académico como hombre de negocios que manifiesta: "tú te vas a hablar con el pez gordo», en cuya persona la reiteración se completa con la negación cuando afirma: «yo no he entrado en esa dinámica» (hombre, universidad no estatal, área científica)

Así pues, se van perpetuando y articulando distintas racionalidades en un sujeto anclado en la tradición (Homo academicus), orientado al resultado (Homo economicus) y vinculado tecnológicamente (Homo digitalis). El académico construye una identidad perdiendo su materialidad, puesto que se convierte en una dirección electrónica, un currículo en la web y un dueño de una parcela en un campo de investigación:

$\mathrm{Y}$, bueno, para investigar en un área tienes que pasarlo bien, tienes que ser capaz de, o sea, tienes que ser capaz de conversar con la persona con quien te gustaría conversar después y tomarte un café, po, y eso no lo puedes manejar. Esas cosas ocurren o no ocurren. Entonces, con el final del tiempo, te vas quedando con colaboradores como con la gente con la que se da no más po, como con las amistades. (Hombre, universidad no estatal, área científica)

\section{Conclusiones}

Los testimonios de los académicos dejan en evidencia una universidad cuyo sentido ha sido sometido a las necesidades del mercado y a una subjetividad que los instrumentaliza como entes productores de indicadores. Esta tensión entre una mirada tradicional del rol de la universidad y del académico y una actitud funcional y enfocada a resultados de corto plazo provoca el despliegue de una identidad donde los resultados personales y la capacidad de moverse dentro de las redes de producción se convierten en las claves que hacen reconocible a un académico.

La consecuencia de todo ello es que, discursivamente, la universidad va siendo (des)poblada de sus académicos, quienes rechazan participar en el gobierno de dichas instituciones y prefieren movilizarse entre ellas para alcanzar mejores posibilidades performativas.

El académico se repliega hacia sí mismo para crear microesferas de autonomía en un intento por negociar su identidad apelando a valores tradicionales de autonomía y libertad académica, en una acción que, paradójicamente, fortalece las bases del sistema que lo somete.

Como trabajador se convierte en un recurso más para la institución, y su valor es transado en el mercado de las relaciones con sus colegas. Su consigna es producir para obtener libertad en una fantasía que no llega a cumplirse, ya 
que la única libertad que obtiene es la de agenciarse, pero queda atrapado en un ciclo donde siempre está en deuda, ya que su posición ante la institución y ante sus colegas depende de los recursos y de las publicaciones que sea capaz de generar.

Este nuevo académico es individualista y está enfocado hacia aquello que provee recursos y poder académico, ya que ha sido obligado a realizar un agenciamiento extremo.

La consecuencia de todo ello es una universidad fracturada y gobernada por indicadores económicos. La formación profesional ya no le pertenece, por cuanto ha sido externalizada para dar espacio a un académico cuya naturaleza identitaria se pone en juego en la producción científica y mediante políticas de apoyo a una gestión donde la inmediatez del resultado determina su valor. En estos escenarios la reflexión social no tiene espacio en el momento de ser evaluada en los rankings y las universidades se transforman en replicantes de modelos sociales.

\section{Referencias bibliográficas}

Acosta, A. (2002). El neointervencionismo estatal en la educación superior en América Latina. Sociológica, 17(49), 43-72.

Alvesson, M. (1999). Methodology for close ups studies: Struggling with closeness and closure. Working paper series institute of economic research. Lund: Lund University.

Becher, T. y Towler, P. (2001). Academic tribes and territories. Buckingham: Open University Press.

Bernasconi, A. (2008). Is There a Latin American Model of the University? Comparative Education Review, 52(1), 27-52.

- (2013). Government and University Autonomy: The Governance Structure of Latin American Public Institutions. En Jorge Balán (ed.). Latin Americass New Knowledge Economy: Higher Education, Government, and International Collaboration (pp. 1-17). Nueva York: Institute for International Education.

Blasi, B. y Romagnosi, S. (2012). Social dynamics in scientific practices: Focus on research groups. Sociologia, 46(2), 66-77.

Blasi, B.; Romagnosi, S. y Bonaccorsi, A. (2017). Playing the ranking game: Media coverage of the evaluation of the quality of research in Italy. Higher Education, 73(5), 741-755. <https://doi.org/10.1007/s10734-016-9991-1>

Bourdieu, P. (2012). Homo academicus. Buenos Aires: Siglo XXI.

BusQuet, J. (2008). Lo sublime y lo vulgar: La cultura de masas o la pervivencia de un mito. Barcelona: UOC.

ButLer, J. (1990). Gender trouble: Feminism and the subversion of identity. Londres: Routledge.

- (2004). Lenguaje, poder e identidad. Madrid: Síntesis.

Byung-Chul, Hun (2017). La sociedad del cansancio. Barcelona: Herder.

Cappello, H. (2015). La identidad universitaria: La construcción del concepto. Revista Internacional de Ciencias Sociales y Humanidades, SOCIOTAM, 25(2), 33-53. 
Castillo, J. y Reyes, M. (2013). Repertorios interpretativos de la teleasistencia domiciliaria (TAD) como práctica de cuidado. Revista Latinoamericana de Psicología Social Ignacio Martín-Baró, 2(2), 149-178.

Charmaz, K. (2006). Constructing grounded theory: A radical guide through qualitative analysis. Londres: Sage.

Court, M. (2004). Talking Back to New Public Management Versions of Accountability in Education: A Co-Principalship's Practices of Mutual Responsibility. Educational Management Administration and Leadership, 2(32), 171-194.

Davies, B. (2000). A body of writing 1990-1991. Oxford: Altamira Press.

De Gaulejac, V. (2002). Lo irreductible social y lo irreductible psíquico. Perfiles Latinoamericanos, 10(21), 49-71.

Denzin, N. (2001). The reflexive interview and a performative social science. Qualitative Research, 1, 23-46.

Galaz, F. (1999). University Experience and the Academic Profession. Revista Electrónica de Investigación Educativa, 1(1). Recuperado de <https://redie.uabc.mx/ redie/article/view/4>.

- (2002). La satisfacción en el trabajo de académicos en una universidad pública estatal. Perfiles Educativos, XXIV(96), 47-72.

González-Casanova. P. (2001). La universidad necesaria en el siglo Xxi. México: Ediciones Era.

Guba, E. y Lincoln, Y. (2008). Paradigmatic controversies, contradictions and emerging confluences. En N. Denzin y Y. Lincoln (eds.). The landscape of qualitative research (pp. 255-286). Londres: Sage Publications.

Guzmán-Valenzuela, C. y Barnett, R. (2013). Academic fragilities in a marketised age: The case of Chile. British Journal of Educational Studies, 61(2), 1-18. <https://doi.org/10.1080/00071005.2013.776006>

Guzmán-Valenzuela, C. y Martínez, M. (2016). Tensiones en la construcción de identidades académicas en una universidad chilena. Estudios Pedagógicos, 42(3), 191-206.

Hood, C. (1995). The «New Public Management» in The 1980s: Variations on a theme. Accounting Organizations and Society, 20(2-3), 93-109.

Holstein, J. y Gubrium, J. (I995). The active interview. Londres: Sage.

- (2006). Interpreting qualitative data: Active interview. Thousand Oaks: Sage.

Ibarra-Colado, E. (2002). Capitalismo académico y globalización: La universidad reinventada. Revista de la Educación Superior, 122(31), 147-154.

Ibarra-Colado, E. y Porter, L. (2007). El debate sobre la evaluación: Del Homo academicus y el Homo economicus. Reencuentro, 48, 34-39.

LARraín, J. (2005). ¿América latina moderna?: Globalización e identidad. Santiago de Chile: LOM.

López, C. (2002). Aproximación al análisis de los discursos profesionales. Signos, 35(51-52), 195-215. <https://doi.org/10.4067/S0718-09342002005100013>

Macfarlane, B. (2011). The morphing of academic practice: Unbundling and the rise of the para-academic. Higher Education Quarterly, 65(1), 59-73. <https://doi.org/10.1111/j.1468-2273.2010.00467.x>

Marginson, S. (2000). Rethinking Academic Work in the Global Era. Journal of Higher Education Policy and Management, 22(1), 23-35.

<https://doi.org/10.1080/713678133> 
- (2006). Engaging democratic education in the neoliberal age. Educational Theory, $56,205-219$. <https://doi.org/10.1111/j.1741-5446.2006.00012.x>

Marginson, S. y Van Der Wende, M. (2007). To Rank or To Be Ranked: The Impact of Global Rankings in Higher Education. Journal of Studies in International Education, 11(3-4), 306-329.

Munita, M.I. y ReYes, J. (2011). El sistema de postgrado en Chile: Evolución y proyecciones para las universidades del Consejo de Rectores. Santiago de Chile: CRUCH ed.

Naidorf, J.; Giordana, P. y Horn, M. (2007). La pertinencia social de la Universidad como categoría equívoca. Nómadas, 27, 22-33.

OCDE (2009). Informe revisión de politicas nacionales de educación: La Educación Superior en Chile. Organización para la Cooperación y el Desarrollo Económico.

Petersen, E. (2012). Re-signifying subjectivity? A narrative exploration of «nontraditional» doctoral students' lived experience of subject formation through two Australian cases. Studies in Higher Education, 39(5), 1-12. <https://doi.org/10.1080/03075079.2012.745337>

Petersen, E. y O'Flynn, G. (2007). The 'good life' and the 'rich portfolio': Young women, schooling and neoliberal subjectification. British Journal of Sociology of Education, 28(4), 459-472. $<$ https://doi.org/10.1080/01425690701369483>

Polkinghorne, D. (1988). Narrative knowing and the human sciences. Nueva York: New York University Press.

Potter, J. y Wetherell, M. (1996). El análisis del discurso y los repertorios interpretativos. En A. Gordo y J. LinazA (comp.). Psicologias, discursos y poder (PDP). Madrid: Visor.

Reynolds, J.; Wetherell, M. y TAYlor, S. (2007). Choice and chance: Negotiating agency in narratives of singleness. The Sociological Review, 55(2), 331-351. <https://doi.org/10.1111/j.1467-954X.2007.00708.x>

Riessman, C.K. (2008). Narrative methods for the human sciences. Thousand Oaks: Sage.

Rodrigo-Alsina, M. (2009). La identidad como patchwork. Revista Cientifica de Información y Comunicación, 6, 285-305.

Rodríguez-Ponce, E. (2011). La Educación Superior en Chile y el rol del mercado: ¿Culpable o inocente? Ingeniare: Revista Chilena de Ingeniería, 20(1), 126-135.

Sisto, V. (2007). Managerialismo y trivialización de la universidad. Nómadas, 27, $8-21$.

- (2008). La investigación como una aventura de producción dialógica: La relación con el otro y los criterios de validación en la metodología cualitativa contemporánea. Psicoperspectivas, 7, 114-136.

Slaughter, Sheila y Leslie, Larry L. (1997). Academic Capitalism, Politics, Policies and the entrepreneurial University. Baltimore y Londres: The Johns Hopkins University Press. 